\title{
Determinants of serum manganese levels in an Italian population
}

\author{
TOMMASO FILIPPINI $^{1}$, BERNHARD MICHALKE ${ }^{2}$, PETER GRILL $^{2}$, CARLOTTA MALAGOLI $^{1}$, \\ MARCELLA MALAVOLTI ${ }^{1}$, LUCIANO VESCOVI $^{3}$, SABINA SIERI $^{4}$, VITTORIO KROGH $^{4}$, \\ ANDREA CHERUBINI $^{5}$, GIUSEPPE MAFFEIS ${ }^{5}$, ROBERTO LUCCHINI ${ }^{6,7}$, \\ MARGHERITA FERRANTE $^{8}$ and MARCO VINCETI ${ }^{1}$
}

\begin{abstract}
${ }^{1}$ CREAGEN, Environmental, Genetic and Nutritional Epidemiology Research Center, Section of Public Health, Department of Biomedical, Metabolic and Neural Sciences, University of Modena and Reggio Emilia, I-41125 Modena, Italy;

${ }^{2}$ Helmholtz Zentrum München, Research Center for Environmental Health, Research Unit Analytical BioGeoChemistry, D-85764 Neuherberg, Germany; ${ }^{3}$ Laboratory of Environmental Chemistry, IREN, I-42123 Reggio Emilia; ${ }^{4}$ Epidemiology and Prevention Unit, Fondazione IRCCS Istituto Nazionale dei Tumori I-20133 Milan; ${ }^{5}$ TerrAria s.r.1., I-20125 Milan;

${ }^{6}$ Section of Occupational Medicine, Department of Medical and Surgical Specialties, Radiological Sciences and Public Health, University of Brescia, I-25125 Brescia, Italy; ${ }^{7}$ Department of Preventive Medicine, Icahn School of Medicine at Mount Sinai, New York, NY 10029, USA; ${ }^{8}$ Department of Medical, Surgical Sciences and Advanced Technologies 'G.F. Ingrassia', University of Catania, I-95123 Catania, Italy
\end{abstract}

Received December 30, 2016; Accepted February 13, 2017

DOI: $10.3892 / \mathrm{mmr} .2017 .6379$

\begin{abstract}
Manganese (Mn) is both essential and toxic for humans, mainly depending on the total levels and its species. Main sources of exposure include food and air pollution, particularly motorized traffic. We sought to determine the potential influence of these sources on serum total levels of $\mathrm{Mn}$ and $\mathrm{Mn}$ species. We selected a random sample of municipality residents from an Italian urban municipality, from whom we collected detailed personal information, dietary habits and a blood sample for serum Mn determination. We also assessed outdoor air Mn exposure, by modeling levels of particulate matter $\leq 10 \mu \mathrm{m}\left(\mathrm{PM}_{10}\right)$ from motorized traffic at the residence of geocoded subjects. Serum Mn species generally showed higher levels in males and positive correlation with age, while no such differences were found according to smoking habits or use of dietary supplements. Among nutrients, only iron intake showed a relation with $\mathrm{Mn}$ [an inverse correlation with Mn-ferritin (Mn-Fer) and a direct one with inorganic-Mn (Inorg-Mn)]. Meat consumption directly correlated and fish and seafood inversely correlated with total Mn, Mn-transferrin (Mn-Tf) and Mn-citrate (Mn-Cit). Fruits and vegetables, including legumes and nuts, generally showed a positive correlation with all $\mathrm{Mn}$ species, especially $\mathrm{Mn}$-Cit, and an inverse one with Inorg-Mn. Odds ratios (ORs) of having
\end{abstract}

Correspondence to: Professor Marco Vinceti, CREAGEN, Environmental, Genetic and Nutritional Epidemiology Research Center, Section of Public Health, Department of Biomedical, Metabolic and Neural Sciences, University of Modena and Reggio Emilia, Via Campi 287, I-41125 Modena, Italy

E-mail: marco.vinceti@unimore.it

Key words: manganese, serum, speciation analysis, cross-sectional study, environmental exposure, particulate matter serum Mn levels above median value increased with increasing $\mathrm{PM}_{10}$ tertiles, with an OR for highest-to-lowest tertile of 7.40 (1.36-40.25) in multivariate analysis. Analyses for Mn species did not highlight a clear comparable pattern. In conclusion, our results seem to demonstrate that $\mathrm{PM}_{10}$ exposure positively influences total Mn serum levels, while single Mn species show conflicting results.

\section{Introduction}

Manganese (Mn) is both an essential and a toxic trace element, mainly depending on its levels in human tissues and its speciation. As a component of enzymes such as superoxide dismutase (SOD), Mn is involved in oxidative stress response and it is also important for the maintenance of a normal bone structure (1). On the other hand, elevated Mn levels may induce neurotoxic effects, including a Parkison-like disease called manganism (2). Mn is a natural component of the environment and one of the main exposure routes is through the diet. Mn is primarily absorbed in the gastrointestinal tract, followed by the lung (3). The main dietary sources are cereals and tubers, fruits and vegetables, followed by meat, fish and seafood (4). Other foods with high Mn content include nuts, dried fruits and seeds, chocolate and tea leaves $(3,5)$. Moreover, intestinal absorption (generally $<10 \%$ of the ingested $\mathrm{Mn}$ ) is influenced by iron storage status and intake (6), calcium or phosphorus intake (7), and by the use of dietary supplements (8), including soy formula (9). Besides dietary intake, Mn exposure may arise from its release into the air, soil and water from industries manufacturing products containing $\mathrm{Mn}$ such as pesticides and $\mathrm{Mn}$ alloys, from mining activities, and from automobile exhausts, leading to environmental contamination of potential public health concern $(10,11)$. Among the toxic metals associated with fine particulate matter (PM) in the ambient 
air (12), there are Mn residues depending on the season and on the sampling site, residential, industrial or rural (13). Finally, tobacco smoke, including second-hand smoke, may expose to Mn at levels higher than those not exposed (14), although not all results are consistent (15).

The attempt to identify reliable biomarkers of Mn exposure yielded conflicting results, since whole blood levels seem to be very variable and of limited value as biomarker of intake (7). Serum and plasma levels could be more sensitive to variations of dietary intake and have half-life ranging between 13-37 days, thus being short-term indicators of exposure (3). A more recent and accurate approach to address the issue of Mn exposure includes analysis of the different Mn species, namely Mn-ferritin (Mn-Fer), Mn-transferrin (Mn-Tf), Mn-citrate (Mn-Cit) and inorganic-Mn (Inorg-Mn) $(10,16)$.

In this cross-sectional study we aimed to assess the influence on serum total levels of $\mathrm{Mn}$ and its species of foods known as major contributors of Mn intake, personal life style and habits, and air pollution, and to investigate the relation between serum Mn and other dietary elements such as iron, calcium and phosphorus.

\section{Materials and methods}

Study participants. The methodology for the recruitment of the study population was previously described $(17,18)$. Briefly, by accessing the databases of the Modena Municipality General Registry Office and following the approval of the local Ethics Committee, we recruited a random sample of 50 subjects residing in Modena, a municipality located in the Emilia-Romagna region ( 180,000 inhabitants). To do that, we randomly selected a list of eligible subjects from each genderand age-specific subgroup of the Modena adult population, using the 'sample' routine of the Stata-11 statistical software (Stata Corp., College Station, TX, USA). We contacted these subjects by phone asking for their participation in the study. The $34 \%$ of subjects who accepted to participate were invited in the morning to the Modena Health Unit for collection of a fasting blood sample after they gave their written consent.

Laboratory analyses. Blood samples were collected in a plastic tube, immediately centrifuged at $1,000 \mathrm{x}$ g for $10 \mathrm{~min}$ and stored as serum aliquots of $1 \mathrm{ml}$ at $-15^{\circ} \mathrm{C}$ until use. We determined serum Mn concentrations at the laboratory of the Research Center for Environmental Health (Research Unit Analytical BioGeoChemistry, Neuherberg, Germany), where a $1 \mathrm{ml}$ aliquot for each study subject was transferred frozen in dry ice, using the previously described methodology $(19,20)$.

Total Mn determination: briefly, we slowly thawed the samples in a refrigerator at $4^{\circ} \mathrm{C}$, vortexed and subsequently diluted $500 \mu \mathrm{l}$ aliquots of samples 1:10 with Milli-Q water (Millipore, Bedford, MA, USA), containing ${ }^{103} \mathrm{Rh}$ as internal standard. The final ${ }^{103} \mathrm{Rh}$ concentration in the diluted serum samples was $1 \mu \mathrm{g} / 1$. An ELEMENT 2 [Thermo Fisher Scientific, Bremen, Germany] inductively coupled plasma-sector field mass spectrometry (ICP-SFMS) instrument was employed for ${ }^{55} \mathrm{Mn}$ determination in medium resolution mode. Sample introduction was carried out using a peristaltic pump connected to a SeaSpray ${ }^{\text {тм }}$ Nebulizer with a cyclon spray chamber (Perkin-Elmer Inc., Waltham, MA, USA). The RF power was set to $1,200 \mathrm{~W}$, the plasma gas was $15 \mathrm{l} / \mathrm{min} \mathrm{Ar}$, whereas the nebuliser gas was $\sim 0.9$ 1/min Ar after daily optimization.

Mn species determination: Mn speciation was performed as previously described (16) using size-exclusion chromatography (SEC) coupled to ICP-dynamic rection cell (DRC)-MS. In short terms, SEC (mass vs. retention time calibrated) was performed with a Knauer 1100 Smartline inert series gradient HPLC system with a $100 \mu 1$ injection loop (Knauer, Berlin, Germany) and further to two serially installed SEC columns separation ranges ca. 200-10 kDa and 2-0.1 kDa. This column combination provided separation of various $\mathrm{Mn}$-proteins from each other and from Mn-Cit as well as the latter clearly from Inorg-Mn. Tris-HAc $(10 \mathrm{mM}, \mathrm{pH} 7.4)+250 \mathrm{mM} \mathrm{NH}_{4} \mathrm{Ac}$ was used as the eluent at a flow-rate of $0.75 \mathrm{ml} / \mathrm{min}$. The column effluent was directly provided to ICP-DRC-MS. A PerkinElmer NexION ICP-MS (Sciex, Toronto, ON, Canada) with dynamic reaction cell capability was employed for on-line determination of ${ }^{55} \mathrm{Mn}$ in the graphic mode. For SEC coupling the column effluent was passing the UV detector and then directed to a Meinhard ${ }^{\circledR}$ nebulizer (Meinhard Co., Golden, CO, USA) (which was mounted to a cyclone spray chamber) using a PEEK transfer tube (ID $100 \mu \mathrm{m}$; Perkin-Elmer Inc.). The RF power was set to $1,250 \mathrm{~W}$, the plasma gas was $15 \mathrm{l} / \mathrm{min}$ Ar. The nebulizer gas was optimized and finally set to $0.98 \mathrm{ml} / \mathrm{min}$ Ar. The dwell time was $500 \mathrm{msec}$. The dynamic reaction cell (DRC) was operated using $\mathrm{NH}_{3}$ as DRC gas, finally at a flow rate of $0.58 \mathrm{ml} / \mathrm{min}$. The DRC band pass (q) was set to 0.45 LOD for Mn-peaks in SEC-ICP-DRC-MS were calculated as $3 \sigma$-criterion and found between $28-35 \mathrm{ng} / \mathrm{l}$, thus, uniformly set to $35 \mathrm{ng} / \mathrm{l}$.

Exposure assessment. We collected from study participants general information including smoking habits, education, occupational history and the use of dietary supplements during the last year. We also assessed their dietary habits through a semi-quantitative food frequency questionnaire used for the Central-Northern Italian population within the EPIC study (21). This questionnaire assessed the frequency and amount of consumption of 188 food items over the previous year, and allowed to estimate frequency and quantity of consumption of the individual foodstuff and related intake of nutrients and contaminants through an ad hoc software $(22,23)$. With regard to the intake of such nutrients, we selected only those previously reported to influence $\mathrm{Mn}$ content, i.e., iron, calcium and phosphorus (6,7). Finally, foodstuff giving the major contribution of Mn intake were selected according to the Mn EFSA scientific opinion and the Italian Total Diet Study $(4,5)$. The food categories included were cereals, meat, fish and seafood, dairy products, chocolate, fruits, vegetables, legumes, nuts and tea consumption.

We also considered the participants exposure to traffic contaminants as a proxy of outdoor Mn exposure, by estimating the concentration of particulate matter $<10 \mu \mathrm{m}\left(\mathrm{PM}_{10}\right)$ at their residences as described elsewhere $(18,24,25)$. Previous studies showed that motor vehicle emissions are important sources of ambient Mn (26,27). We implemented this approach since traffic was expected to be by far the main source of exposure for this population, also for the absence of major industrial emissions in the study area. To do that, we took into account the road distribution and the location of the municipal solid waste incinerator and its modeled emissions (28). Briefly, 
we used Google Earth to geocode the home address of all study subjects and we modeled the average ambient air $\mathrm{PM}_{10}$ concentration at these locations for 2006, using the CAlifornia LINE version 4 (CALINE4 air quality dispersion model; CALTRANS 1989, California Department of Transportation) air quality dispersion model for roads and other linear sources (29). The 2006 assessment carried out in Modena (24) was generated by a model including: i) demographic and occupational information for all residents of the provinces; ii) detailed personal mobility information collected by the National Institute of Statistics 2001 Census; and iii) validated through ad hoc surveys and automatic vehicle counters. The model yielded a matrix of vehicle movements for each road, based on daily movements estimated for the residents of Modena considering their age, gender, family structure and occupation (30). This model was validated in the study area by comparing measured and modeled $\mathrm{PM}_{10}$ levels in the air monitoring stations (24). Limited changes occurred in the municipal area with respect to circulating vehicles (from $117,310-115,887$ ) and to the census of adult population (from $152,372-155,998)$, since the year of exposure assessment (2006) until the beginning of the study (2011), according to the data released by the Modena municipality (www.comune.modena. it/serviziostatistica/pubblicazioni/annuari/annuario2012/incidenti2012/inci_tav2012.shtml).

Data analysis. We calculated median and interquartile range (IQR) for total Mn and for all Mn species. Since we found a subject showing an extremely high level of total Mn $(22.6 \mu \mathrm{g} / \mathrm{l})$, we considered this sample as an outlier and removed it from data analyses. Pearson's coefficients and 95\% confidence intervals (CI) were calculated between $\mathrm{Mn}$ species and continuous variables (age, BMI, energy and food and nutrients intake, estimates of $\mathrm{PM}_{10}$ ). Influence of several dietary items and nutrients were tested also using bivariate and multivariate regression models. In order to reduce the influence of measurement errors that are frequently produced by food frequency questionnaires, we adjusted the estimates of dietary nutrients, e.g., iron intake, for total energy intake, using Willett's residual method (31). In order to test the effect of outdoor environmental Mn levels on the serum levels of the different $\mathrm{Mn}$ species, we performed bivariate and multivariate logistic regression analysis using as endpoint the odds ratio (OR) of being above the median value of the Mn species.

When Mn species had values below the limit of detection $(0.04 \mu \mathrm{g} / \mathrm{l})$, they were set to $0.02(=\mathrm{LOD} / 2)$. We carried out sensitivity analyses with different methods, i.e., by replacing LOD/ 2 with zero or by dividing it by $\sqrt{2}$, and/or the use of log-transformed values, and finally with winsorized values by setting data exceeding the 5 th/95th percentile to the 5 th/95th percentile. Dealing with censored data in some Mn-species, we tested also the tobit regression ('tobit' routine in STATA-14), which is specifically designed to estimate linear relations between variables when there is either left or right censoring in the dependent variable $(32,33)$.

\section{Results}

Table I summarizes the main characteristic of the study population. Age ranged between $35-70$ years with mean \pm SD value
Table I. Characteristics of study population.

\begin{tabular}{|c|c|}
\hline Study population & $\mathrm{n}(\%)$ \\
\hline All subjects & $50(100)$ \\
\hline \multicolumn{2}{|l|}{ Gender } \\
\hline Males & $26(52)$ \\
\hline Females & $24(48)$ \\
\hline \multicolumn{2}{|l|}{ Age (years) } \\
\hline $35-49$ & $22(44)$ \\
\hline $50-70$ & $28(56)$ \\
\hline \multicolumn{2}{|l|}{ BMI } \\
\hline$<18.5$ & $1(2)$ \\
\hline $18.5-24.9$ & $21(42)$ \\
\hline$>25$ & $28(56)$ \\
\hline \multicolumn{2}{|l|}{ Education } \\
\hline Elementary school & $3(6)$ \\
\hline Middle school & $10(20)$ \\
\hline High school & $23(46)$ \\
\hline College or higher & $14(28)$ \\
\hline \multicolumn{2}{|l|}{ Occupation } \\
\hline Agriculture & $0(0)$ \\
\hline Industry & $6(12)$ \\
\hline Services $^{\mathrm{a}}$ & $27(53)$ \\
\hline Housewife & $2(4)$ \\
\hline Retired & $11(21)$ \\
\hline Other & $5(10)$ \\
\hline \multicolumn{2}{|l|}{ Smoking habits } \\
\hline Never smokes & $25(50)$ \\
\hline Former smokers & $16(32)$ \\
\hline Current smokers & $9(18)$ \\
\hline \multicolumn{2}{|l|}{ Mn supplement users } \\
\hline Not users & $42(84)$ \\
\hline Users & $8(16)$ \\
\hline
\end{tabular}

${ }^{\mathrm{a}}$ Health, education and business.

of $52.3( \pm 10.4)$, with males and females equally represented. Eight subjects reported consumption of dietary supplements containing a mean value of $1.25 \mathrm{mg} / \mathrm{day}$ of $\mathrm{Mn}$ (in the form of Mn sulphate monohydrate) at the time of the sampling. Distribution of total Mn serum levels and specific species are presented in Table II. Overall, total $\mathrm{Mn}$ ranged from $0.72-8.18 \mu \mathrm{g} / 1$, with median value of 2.32 (IQR, 1.81-3.06). Total Mn levels and Mn-Tf show slightly higher levels in males and in people aged $\geq 50$ years, while no relevant difference was detected according to BMI categories or smoking habits independently from supplement use, whereas Mn-Fer, Mn-Cit and Inorg-Mn showed little variation among the categories.

$\mathrm{Mn}$ total level positively correlated with individual Mn species except for Inorg-Mn, which demonstrated a negative correlation with Total $\mathrm{Mn}$ and with the other species. Moreover, Mn-Cit shows a positive correlation with both Mn-Fer and Mn-Tf, which in turn directly correlated with 
Table II. Distribution with median (50th) and interquartile range (IQR) of total serum Mn and its species in overall population and selected subgroups (values in $\mu \mathrm{g} / \mathrm{l}$ ).

\begin{tabular}{|c|c|c|c|c|c|c|c|c|c|c|}
\hline \multirow[b]{2}{*}{ Study subjects (N) } & \multicolumn{2}{|c|}{ Total Mn } & \multicolumn{2}{|c|}{ Mn-Fer } & \multicolumn{2}{|c|}{$\mathrm{Mn}-\mathrm{Tf}$} & \multicolumn{2}{|c|}{ Mn-Cit } & \multicolumn{2}{|c|}{ Inorg-Mn } \\
\hline & 50 th & IQR & 50th & IQR & 50 th & IQR & 50th & IQR & 50th & IQR \\
\hline All participants & 2.36 & $(1.81-3.06)$ & 0.33 & $(0.13-0.55)$ & 0.76 & $(0.18-1.24)$ & 0.55 & $(0.24-0.84)$ & 0.20 & $(0.02-0.62)$ \\
\hline \multicolumn{11}{|l|}{ Gender } \\
\hline Males (26) & 2.47 & $(2.06-3.06)$ & 0.28 & $(0.15-0.37)$ & 0.84 & $(0.21-1.32)$ & 0.55 & $(0.27-0.83)$ & 0.16 & $(0.02-0.59)$ \\
\hline Females (24) & 2.07 & $(1.65-3.39)$ & 0.40 & $(0.11-1.12)$ & 0.55 & $(0.11-1.11)$ & 0.54 & $(0.14-0.88)$ & 0.24 & $(0.10-0.75)$ \\
\hline \multicolumn{11}{|l|}{ Age (years) } \\
\hline$<50(22)$ & 2.27 & $(1.70-2.68)$ & 0.29 & $(0.15-0.43)$ & 0.43 & $(0.17-1.45)$ & 0.50 & $(0.09-1.12)$ & 0.19 & $(0.15-0.54)$ \\
\hline$\geq 50(28)$ & 2.42 & $(1.97-3.80)$ & 0.35 & $(0.12-0.56)$ & 0.87 & $(0.19-1.23)$ & 0.56 & $(0.27-0.78)$ & 0.21 & $(0.02-1.10)$ \\
\hline \multicolumn{11}{|l|}{ BMI } \\
\hline$<25(22)$ & 2.13 & $(1.60-2.68)$ & 0.27 & $(0.11-0.55)$ & 0.64 & $(0.18-1.09)$ & 0.54 & $(0.12-0.75)$ & 0.37 & $(0.05-0.62)$ \\
\hline$\geq 25(28)$ & 2.42 & $(1.98-3.80)$ & 0.35 & $(0.14-0.56)$ & 0.91 & $(0.17-1.63)$ & 0.56 & $(0.24-1.12)$ & 0.17 & $(0.02-0.64)$ \\
\hline \multicolumn{11}{|l|}{ Smoking habits } \\
\hline Non-smokers (25) & 2.32 & $(2.05-3.18)$ & 0.35 & $(0.12-0.56)$ & 0.76 & $(0.26-1.45)$ & 0.53 & $(0.24-1.30)$ & 0.21 & $(0.02-0.64)$ \\
\hline Ex-smokers (16) & 2.29 & $(1.71-3.03)$ & 0.37 & $(0.11-0.51)$ & 0.24 & $(0.09-1.13)$ & 0.56 & $(0.17-0.89)$ & 0.47 & $(0.02-1.08)$ \\
\hline Smokers (9) & 2.10 & $(1.78-2.63)$ & 0.23 & $(0.22-0.35)$ & 0.91 & $(0.18-1.24)$ & 0.57 & $(0.26-0.71)$ & 0.16 & $(0.02-0.29)$ \\
\hline \multicolumn{11}{|l|}{ Mn supplement users } \\
\hline No (42) & 2.29 & $(1.93-3.18)$ & 0.32 & $(0.14-0.56)$ & 0.68 & $(0.17-1.28)$ & 0.56 & $(0.24-0.84)$ & 0.21 & $(0.02-0.64)$ \\
\hline Yes (8) & 2.39 & $(1.73-2.45)$ & 0.35 & $(0.11-0.55)$ & 0.82 & $(0.24-0.96)$ & 0.46 & $(0.06-0.93)$ & 0.16 & $(0.02-0.58)$ \\
\hline
\end{tabular}

IQR, interquartile range; Mn-Fer, Mn-ferritin; Mn-Tf, Mn-transferrin; Mn-Cit, Mn-citrate; Inorg-Mn, inorganic-Mn.

Table III. Pearson's correlation coefficients (r) and 95\% confidence intervals (CI) between total serum Mn and its species.

\begin{tabular}{|c|c|c|c|c|}
\hline & Mn-Fer & Mn-Tf & Mn-Cit & Inorg-Mn \\
\hline $\mathrm{Mn}-\mathrm{Fer}$ & 1 & & & \\
\hline $\mathrm{Mn}-\mathrm{Tf}$ & $\begin{array}{c}0.222 \\
(-0.063 \text { to } 0.473) \\
P=0.126\end{array}$ & 1 & & \\
\hline Mn-Cit & $\begin{array}{c}0.204 \\
(-0.082 \text { to } 0.459) \\
P=0.160\end{array}$ & $\begin{array}{c}0.259 \\
(-0.024 \text { to } 0.504) \\
P=0.072\end{array}$ & 1 & \\
\hline Inorg-Mn & $\begin{array}{c}-0.193 \\
(-0.449 \text { to } 0.094) \\
P=0.185\end{array}$ & $\begin{array}{c}-0.332 \\
(-0.561 \text { to }-0.056) \\
P=0.020\end{array}$ & $\begin{array}{c}-0.145 \\
(-0.409 \text { to } 0.142) \\
P=0.314\end{array}$ & 1 \\
\hline Total Mn & $\begin{array}{c}0.462 \\
(0.208 \text { to } 0.658) \\
\mathrm{P}<0.001\end{array}$ & $\begin{array}{c}0.676 \\
(0.487 \text { to } 0.804) \\
\mathrm{P}<0.001\end{array}$ & $\begin{array}{c}0.694 \\
(0.512 \text { to } 0.816) \\
\mathrm{P}<0.001\end{array}$ & $\begin{array}{c}0.091 \\
(-0.195 \text { to } 0.363) \\
P=0.534\end{array}$ \\
\hline
\end{tabular}

CI, confidence intervals; Mn-Fer, Mn-ferritin; Mn-Tf, Mn-transferrin; Mn-Cit, Mn-citrate; Inorg-Mn, inorganic-Mn.

each other (Table III, Fig. 1). Sensitivity analyses, using a different substitution method for values below the LOD, or log or winsorized transformation did not alter the results (data not shown).

Correlations of Mn species with individual characteristics and dietary factors are reported in Table IV. Generally, age demonstrated a strong positive relation with all but one Mn species, while no association emerged for BMI. Total energy intake showed a strong correlation only with Inorg-Mn, while among nutrients, iron intake showed an inverse relation with Mn-Fer and a positive one with Inorg-Mn. Phosphate was slightly inversely associated with all Mn-species except Mn-Tf, while calcium did not show such strong correlation. Finally, Table V showed Pearson's correlation coefficients of Mn with 

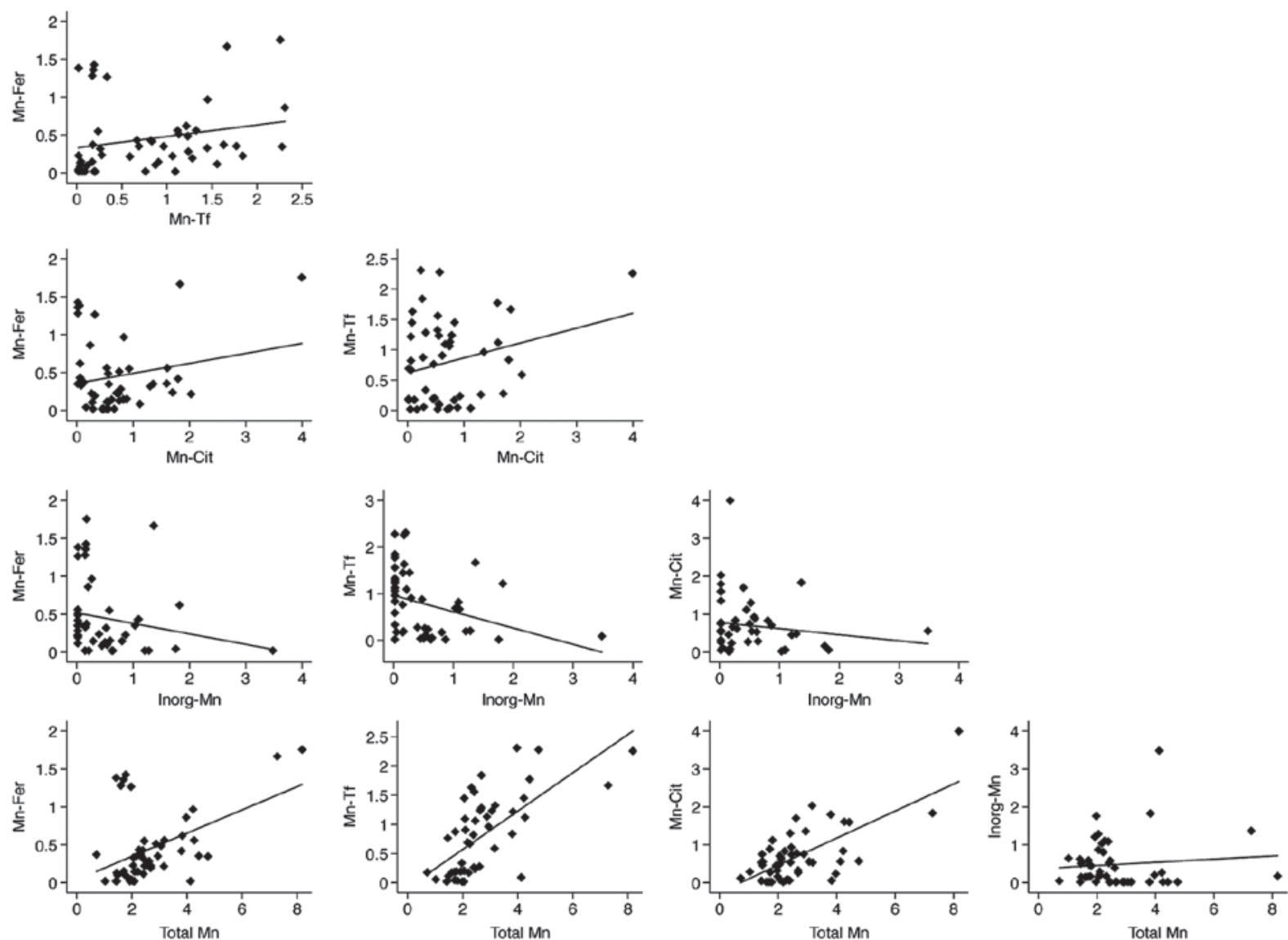

Figure 1. Scatter plots between total serum Mn and its species ( $\mu \mathrm{g} / \mathrm{l}$ ) with linear regression fitted values (solid line). Mn-Fer, Mn-ferritin; Mn-Tf, Mn-transferrin; Mn-Cit, Mn-citrate; Inorg-Mn, inorganic-Mn.

the main food items. Generally, cereals and dairy products intake did not correlate with Mn serum levels. Meat consumption demonstrated an inverse relation with Mn-Fer levels, while a positive one emerged for Inorg-Mn. Also fish and seafood showed an inverse relation with total Mn, mainly for $\mathrm{Mn}$-Cit and Mn-Tf. Fruit intake demonstrated a positive correlation with all Mn species, except with Inorg-Mn. Similar results were found for vegetable intake, showing a positive relation with Mn-Tf and Mn-Cit and an inverse one with Inorg-Mn. Pulse and nut intake positively correlated with quite all $\mathrm{Mn}$-species, mainly with Mn-Cit. Finally chocolate and tea consumption demonstrated little correlation with Mn-species. In general, this was true both for linear and tobit regression analyses, and in both bivariate and multivariate analyses, adjusted for age, gender and total energy intake (data not shown).

OR of having serum levels of Mn species above the median value for increasing $\mathrm{PM}_{10}$ tertile are shown in Table VI, Fig. 2. For total Mn, OR increased with increasing $\mathrm{PM}_{10}$ tertiles. When Mn species were considered, Mn-Fer and Inorg-Mn showed an increased OR in the intermediate category, but a decreased risk in the highest category, while Mn-Tf and Mn-Cit showed a decreased OR in both intermediate and highest categories.

\section{Discussion}

An adequate assessment of $\mathrm{Mn}$ exposure is an important public health issue, for which evidence is still rather limited (34-36). Serum total Mn distribution in our random sample of Modena municipality is similar or slightly higher than those reported in previous Italian (37-40) and European adult populations (41-48), as we found a median/mean value of 2.32/2.68 $\mu \mathrm{g} / 1$, while other studies reported median/mean values ranging from 0.18 to $3.30 \mu \mathrm{g} / \mathrm{l}$. These results also allow to rule out any contamination of our samples during their collection and management, as frequently occurred when using serum specimens $(49,50)$, also taking into account the results of a recent study on healthy subjects (51).

Interestingly, similarly to our previous findings (16), we observed a switch in Mn-carrier from Mn-Tf to Mn-Cit at increasing concentration of Total Mn (data not shown). Moreover, Mn-Tf demonstrated a stronger correlation for values below the cut point of $4 \mu \mathrm{g} / \mathrm{l}$, whereas above this value it no longer increased, while Mn-Cit showed an opposite behavior. In accordance with previous studies, the present results show no significant gender-related difference in serum Mn levels, despite a slightly higher concentration in males. Similarly to other studies, no relevant differences in Mn levels were detected according to age $(41,43)$, BMI $(52)$ or smoking habits of study participants $(41,46,53)$. Conversely, the use of Mn-containing supplements seems not to affect the Mn serum levels, differently from what was expected (8).

Our study subjects were fasting because the blood samples were taken in the morning, however, to our knowledge, no author has described either any influence of an omitted meal on $\mathrm{Mn}$ serum concentration or a circadian variation for the element. In contrast to the high variation demonstrated by 
Table IV. Pearson's correlation coefficients (r) and 95\% confidence intervals (CI) between Mn serum species and characteristic and nutrients intake of study subjects.

\begin{tabular}{|c|c|c|c|}
\hline & $\mathrm{r}$ & $95 \% \mathrm{CI}$ & P-value \\
\hline \multicolumn{4}{|l|}{ Age } \\
\hline Total Mn & 0.307 & $(0.028$ to 0.541$)$ & 0.032 \\
\hline Mn-Fer & 0.235 & $(-0.049$ to 0.485$)$ & 0.126 \\
\hline Mn-Tf & 0.194 & $(-0.092$ to 0.451$)$ & 0.181 \\
\hline Mn-Cit & 0.146 & $(-0.141$ to 0.410$)$ & 0.319 \\
\hline Inorg-Mn & 0.097 & $(-0.189$ to 0.368$)$ & 0.508 \\
\hline \multicolumn{4}{|c|}{ Total energy intake } \\
\hline Total Mn & 0.038 & $(-0.246$ to 0.315$)$ & 0.798 \\
\hline Mn-Fer & -0.179 & $(-0.438$ to 0.107$)$ & 0.217 \\
\hline Mn-Tf & -0.170 & $(-0.431$ to 0.116$)$ & 0.242 \\
\hline Mn-Cit & 0.072 & $(-0.213$ to 0.347$)$ & 0.621 \\
\hline Inorg-Mn & 0.376 & $(0.106$ to 0.595$)$ & 0.008 \\
\hline \multicolumn{4}{|c|}{ Calcium intake } \\
\hline Total Mn & -0.104 & $(-0.375$ to 0.182$)$ & 0.476 \\
\hline Mn-Fer & -0.112 & $(-0.381$ to 0.175$)$ & 0.443 \\
\hline $\mathrm{Mn}-\mathrm{Tf}$ & 0.164 & $(-0.123$ to 0.425$)$ & 0.262 \\
\hline Mn-Cit & -0.121 & $(-0.390$ to 0.165$)$ & 0.404 \\
\hline Inorg-Mn & -0.156 & $(-0.419$ to 0.131$)$ & 0.285 \\
\hline \multicolumn{4}{|l|}{ BMI } \\
\hline Total Mn & 0.029 & $(-0.254$ to 0.308$)$ & 0.843 \\
\hline Mn-Fer & 0.026 & $(-0.258$ to 0.304$)$ & 0.862 \\
\hline Mn-Tf & -0.041 & $(-0.318$ to 0.243$)$ & 0.783 \\
\hline Mn-Cit & 0.110 & $(-0.176$ to 0.380$)$ & 0.451 \\
\hline Inorg-Mn & 0.035 & $(-0.249$ to 0.313$)$ & 0.811 \\
\hline \multicolumn{4}{|l|}{ Iron intake } \\
\hline Total Mn & 0.047 & $(-0.238$ to 0.324$)$ & 0.751 \\
\hline Mn-Fer & -0.188 & $(-0.445$ to 0.099$)$ & 0.196 \\
\hline Mn-Tf & -0.046 & $(-0.323$ to 0.239$)$ & 0.756 \\
\hline Mn-Cit & 0.001 & $(-0.281$ to 0.282$)$ & 0.997 \\
\hline Inorg-Mn & 0.255 & $(-0.028$ to 0.501$)$ & 0.077 \\
\hline \multicolumn{4}{|c|}{ Phosphate intake } \\
\hline Total Mn & -0.203 & $(-0.458$ to 0.083$)$ & 0.162 \\
\hline Mn-Fer & -0.230 & $(-0.480$ to 0.055$)$ & 0.112 \\
\hline Mn-Tf & 0.002 & $(-0.279$ to 0.283$)$ & 0.988 \\
\hline Mn-Cit & -0.199 & $(-0.455$ to 0.087$)$ & 0.171 \\
\hline Inorg-Mn & -0.017 & $(-0.297$ to 0.265$)$ & 0.906 \\
\hline
\end{tabular}

CI, confidence intervals; Mn-Fer, Mn-ferritin; Mn-Tf, Mn-transferrin; $\mathrm{Mn}$-Cit, Mn-citrate; Inorg-Mn, inorganic-Mn.

Mn whole blood concentrations that seemed to be extremely variable which may preclude it as a viable status indicator (7), serum Mn concentration appeared to be somewhat sensitive to large variations in $\mathrm{Mn}$ intake and response to dietary intake (8). Moreover, among the several biomarkers investigated in human studies, only hair $(54,55)$ and plasma or serum were representative of $\mathrm{Mn}$ average exposure, with corresponding half-life between 13-37 days of serum Mn levels (3).
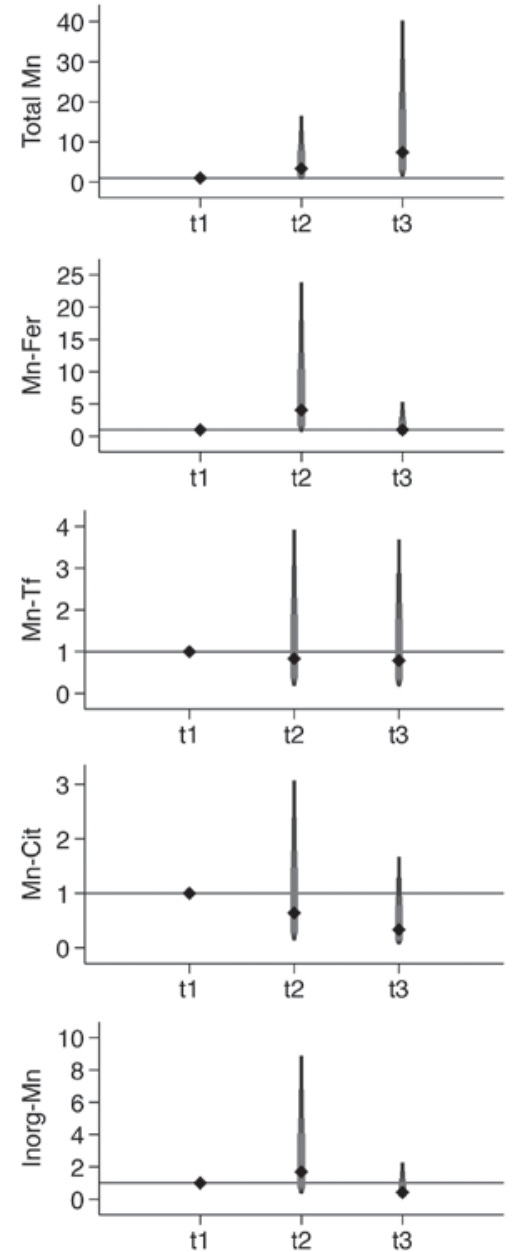

Figure 2. ORs with $95 \%$ CI for Mn species above median with increasing tertiles of $\mathrm{PM}_{10}$. ORs for model adjusted for age, gender, total energy and iron intake, smoking habits and cadmium serum levels is reported. ORs, odds ratios; CI confidence intervals; $\mathrm{PM}_{10}$, particulate matter $\leq 10 \mu \mathrm{m}$; Mn-Fer, Mn-ferritin; Mn-Tf, Mn-transferrin; Mn-Cit, Mn-citrate; Inorg-Mn, inorganic-Mn.

The regulation of $\mathrm{Mn}$ absorption is very efficient and appears to be one of the adaptive responses to dietary $\mathrm{Mn}$ intake, and such regulation allows Mn homeostasis to be maintained over a wide range of intakes (7). The main food contributors ( $>5 \%$ of the total intake) to Mn intake in European population and in particular in Northern Italy, are cereal-based products, vegetables, fruits, fruit products and beverages (coffee, tea, alcoholic beverages) $(4,5)$. In our population we did not clearly identify a positive relation between Mn levels and cereal consumption, while vegetable intake, especially legumes, and partially dry fruits (nuts), showed a positive relation. Interestingly, we observed an inverse relation of $\mathrm{Mn}$ serum levels with meat and fish and seafood consumption, possibly reflecting the influence of iron intake. Consistently, when we performed a regression model between meat intake and $\mathrm{Mn}$ levels, the inclusion of iron intake in the model toned down the observed inverse relation (data not shown). Also, serum ferritin has been noted to be inversely associated with blood Mn concentration (56). Finally, in out study tea and chocolate consumption was not associated with the serum Mn levels, although about one third of the study participants reported no tea consumption, so weakening our possibility to find any association. 
Table V. Pearson's coefficients coefficients (r) and 95\% confidence intervals (CI) between total serum Mn and its species with food intake of study subjects.

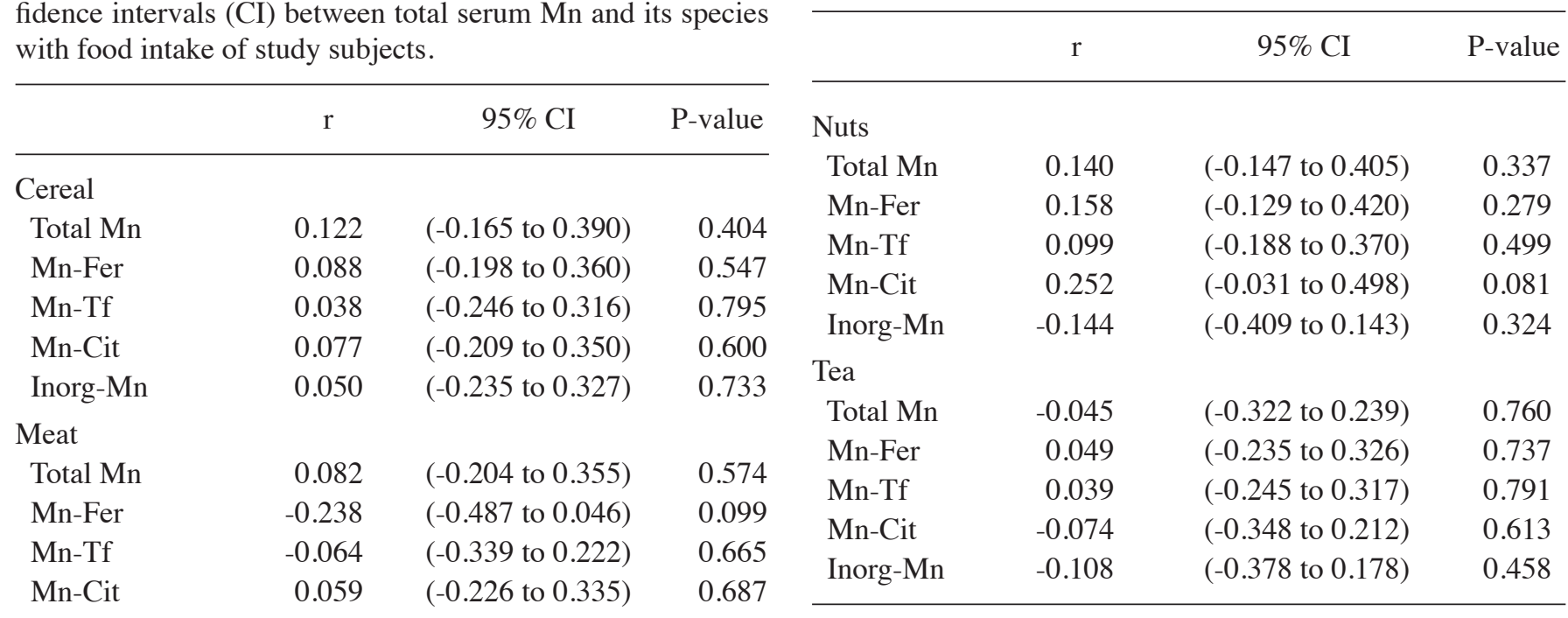

Inorg-Mn

0.306

(0.027 to 0.541$)$

0.032

Fish and seafood

$\begin{array}{lrrr}\text { Total Mn } & -0.217 & (-0.470 \text { to } 0.068) & 0.134 \\ \text { Mn-Fer } & 0.059 & (-0.226 \text { to } 0.334) & 0.688 \\ \text { Mn-Tf } & -0.197 & (-0.453 \text { to } 0.090) & 0.176 \\ \text { Mn-Cit } & -0.207 & (-0.461 \text { to } 0.079) & 0.154 \\ \text { Inorg-Mn } & -0.036 & (-0.314 \text { to } 0.248) & 0.806\end{array}$

Milk and dairy

products

Total

Mn-Fer

$-0.087$

$(-0.359$ to 0.199$)$

0.552

$(-0.345$ to 0.215$)$

(-0.348 to 0.211$)$

$\mathrm{Mn}-\mathrm{Tf}$

$-0.075$

Mn-Cit

$-0.040$

$(-0.317$ to 0.244$)$

Inorg-Mn

$-0.011$

$(-0.291$ to 0.271$)$

Chocolate

Total Mn

Mn-Fer

$\mathrm{Mn}-\mathrm{Tf}$

Mn-Cit

Inorg-Mn

Fruit

$\begin{array}{lr}\text { Total Mn } & 0.13 \\ \text { Mn-Fer } & 0.13 \\ \text { Mn-Tf } & 0.02 \\ \text { Mn-Cit } & 0.148 \\ \text { Inorg-Mn } & -0.023 \\ \text { Vegetables } & \\ \text { Total Mn } & 0.34 \\ \text { Mn-Fer } & 0.157 \\ \text { Mn-Tf } & 0.246 \\ \text { Mn-Cit } & 0.38 \\ \text { Inorg-Mn } & -0.192 \\ \text { Legumes } & \\ \text { Total Mn } & 0.316 \\ \text { Mn-Fer } & 0.175 \\ \text { Mn-Tf } & 0.120 \\ \text { Mn-Cit } & 0.302 \\ \text { Inorg-Mn } & 0.182\end{array}$

$-0.110$

$-0.161$

0.015

$-0.194$

0.082

(-0.380 to 0.176$)$

$(-0.423$ to 0.126$)$

$(-0.267$ to 0.295$)$

$(-0.267$ to 0.295$)$

(-0.204 to 0.355$)$

0.629

0.611

0.786

0.943

0.451

0.270

0.919

0.182

0.574

(-0.148 to 0.404$)$

0.341

$(-0.153$ to 0.400$) \quad 0.361$

$(-0.263$ to 0.299$) \quad 0.892$

$(-0.139$ to 0.412$) \quad 0.311$

(-0.302 to 0.260$) \quad 0.875$

$0.342 \quad(0.067$ to 0.568$)$

0.157

0.246

0.388

$-0.192$

$(-0.130$ to 0.420$)$

(-0.038 to 0.493$)$

(0.120 to 0.603$)$

(-0.449 to 0.095$)$

0.016

0.282

0.089

0.006

0.187

0.316

(0.038 to 0.548$)$

0.027

$(-0.112$ to 0.434$)$

$(-0.167$ to 0.388$)$

0.230

0.412

(0.022 to 0.537$)$

0.035

(-0.105 to 0.441$)$
Table V. Continued.

CI, confidence intervals; Mn-Fer, Mn-ferritin; Mn-Tf, Mn-transferrin; Mn-Cit, Mn-citrate; Inorg-Mn, inorganic-Mn.

The assessment of air-Mn in order to evaluate the influence of air pollution on human Mn exposure and the related health implications is of relevant and growing interest. Previous Italian studies, which assessed levels of $\mathrm{PM}_{10}$ air-Mn using motor neuron function in the higher exposed group of both elderly (57) and adolescents (58), as well an increased risk of asthma only in the youngest population (35). More recently, in the absence of facility emissions data for individual study subjects, a US study used the long-term air measurements available from local air monitoring stations in order to derive receptor-specific concentrations of respirable air Mn through total suspended particulates (TSP), $\mathrm{PM}_{10}$ and $\mathrm{PM}_{2.5}$ (59).

Our results indicate that increasing tertiles of $\mathrm{PM}_{10}$ exposure are likely to be associated with Mn serum levels above the median, but only when total Mn is considered. Similarly, a study carried out in Canada showed that geographic regions with higher levels of airborne Mn contributed positively to total Mn blood levels (60) and a recent study carried out in welders showed that plasma Mn correlates with air-Mn during occupational exposure (61). However, in the present study the relation between increasing $\mathrm{PM}_{10}$ tertiles and serum $\mathrm{Mn}$ was less evident when Mn species were considered, especially for $\mathrm{Mn}$-Cit and $\mathrm{Mn}$-Tf which demonstrated an inverse trend with respect to total Mn, while Mn-Fer and Inorg-Mn analyses yielded some evidence of a direct relation but no clear dose-response association. A possible explanation of these conflicting results could be associated to the fact that total Mn is not simply the sum of considered Mn carriers, but it includes additional Mn chemical forms. Actually, overall $\mathrm{Mn}$ in serum could be bound to $\alpha-2$-macroglobulin and also to albumin fraction, thus other non-measured Mn species could be influenced by airborne-Mn and may explain the positive association highlighted only for total $\mathrm{Mn}$.

A strength of our study for Mn exposure assessment was the analysis of various Mn species in serum (16). The switch from the overall content of a trace element to the single a 24-h personal sampling, reported deficits in olfactory and 
Table VI. Odds ratios (ORs) and 95\% confidence intervals (CI) for having Mn species above the median value and increasing tertiles of estimated $\mathrm{PM}_{10}$. Median estemated $\mathrm{PM}_{10}$ values $\left(\mu \mathrm{g} / \mathrm{m}^{3}\right)$ for each tertile and median value $(\mu \mathrm{g} / \mathrm{l})$ for each Mn species is reported for each tertile.

\begin{tabular}{|c|c|c|c|c|}
\hline & \multicolumn{3}{|c|}{$\mathrm{PM}_{10}$ tertiles (median) } & \multirow[b]{2}{*}{$\mathrm{P}$ trend } \\
\hline & I (11.06) & II (14.22) & III (18.37) & \\
\hline \multicolumn{5}{|l|}{ Total Mn } \\
\hline Median & 2.05 & 2.37 & 2.46 & \\
\hline Crude model & 1.00 & $3.09(0.73-12.98)$ & $5.28(1.20-23.32)$ & 0.105 \\
\hline Adjusted model $^{\mathrm{a}}$ & 1.00 & $2.78(0.60-12.90)$ & $5.43(1.15-25.91)$ & 0.124 \\
\hline Adjusted model $^{\mathrm{b}}$ & 1.00 & $2.91(0.62-13.76)$ & $5.47(1.15-25.91)$ & 0.118 \\
\hline Adjusted model ${ }^{\mathrm{c}}$ & 1.00 & $3.46(0.69-17.26)$ & $7.54(1.37-41.57)$ & 0.085 \\
\hline Adjusted model ${ }^{\mathrm{d}}$ & 1.00 & $3.35(0.68-16.53)$ & $7.40(1.36-40.25)$ & 0.094 \\
\hline \multicolumn{5}{|l|}{ Mn-Fer } \\
\hline Median & 0.23 & 0.40 & 0.25 & \\
\hline Crude model & 1.00 & $1.87(0.47-7.53)$ & $0.87(0.22-3.45)$ & 0.101 \\
\hline Adjusted model $^{\mathrm{a}}$ & 1.00 & $3.07(0.61-15.48)$ & $0.80(0.17-3.83)$ & 0.200 \\
\hline Adjusted model $^{\mathrm{b}}$ & 1.00 & $3.21(0.63-16.37)$ & $0.80(0.16-3.88)$ & 0.203 \\
\hline Adjusted model ${ }^{\mathrm{c}}$ & 1.00 & $3.76(0.70-20.15)$ & $0.97(0.19-5.04)$ & 0.262 \\
\hline Adjusted model $^{\mathrm{d}}$ & 1.00 & $4.06(0.69-23.82)$ & $1.01(0.19-5.35)$ & 0.268 \\
\hline \multicolumn{5}{|l|}{ Mn-Tf } \\
\hline Median & 0.76 & 0.79 & 0.75 & \\
\hline Crude model & 1.00 & $0.89(0.23-3.49)$ & $0.89(0.23-3.49)$ & 0.996 \\
\hline Adjusted model $^{\mathrm{a}}$ & 1.00 & $0.88(0.20-4.00)$ & $0.86(0.20-3.74)$ & 0.713 \\
\hline Adjusted model $^{\mathrm{b}}$ & 1.00 & $0.96(0.20-4.54)$ & $0.85(0.19-3.82)$ & 0.636 \\
\hline Adjusted model ${ }^{\mathrm{c}}$ & 1.00 & $0.90(0.18-4.42)$ & $0.76(0.16-3.74)$ & 0.704 \\
\hline Adjusted model $^{\mathrm{d}}$ & 1.00 & $0.83(0.18-3.92)$ & $0.79(0.17-3.68)$ & 0.754 \\
\hline \multicolumn{5}{|l|}{ Mn-Cit } \\
\hline Median & 0.71 & 0.54 & 0.49 & \\
\hline Crude model & 1.00 & $0.70(0.18-2.77)$ & $0.54(0.14-2.17)$ & 0.117 \\
\hline Adjusted model $^{\mathrm{a}}$ & 1.00 & $0.81(0.19-3.50)$ & $0.52(0.12-2.19)$ & 0.099 \\
\hline Adjusted model $^{\mathrm{b}}$ & 1.00 & $0.72(0.16-3.26)$ & $0.51(0.12-2.21)$ & 0.081 \\
\hline Adjusted model $^{\mathrm{c}}$ & 1.00 & $0.59(0.13-2.79)$ & $0.35(0.07-1.73)$ & 0.030 \\
\hline Adjusted model $^{\mathrm{d}}$ & 1.00 & $0.64(0.13-3.07)$ & $0.33(0.07-1.67)$ & 0.022 \\
\hline \multicolumn{5}{|l|}{ Inorg-Mn } \\
\hline Median & 0.45 & 0.23 & 0.08 & \\
\hline Crude model & 1.00 & $0.90(0.23-3.58)$ & $0.42(0.10-1.70)$ & 0.312 \\
\hline Adjusted model $^{\mathrm{a}}$ & 1.00 & $1.43(0.30-6.76)$ & $0.34(0.07-1.64)$ & 0.240 \\
\hline Adjusted model $^{\mathrm{b}}$ & 1.00 & $1.34(0.27-6.53)$ & $0.33(0.07-1.60)$ & 0.207 \\
\hline Adjusted model ${ }^{c}$ & 1.00 & $1.66(0.32-8.68)$ & $0.46(0.09-2.42)$ & 0.400 \\
\hline Adjusted model $^{\mathrm{d}}$ & 1.00 & $1.69(0.32-8.88)$ & $0.42(0.08-2.29)$ & 0.339 \\
\hline
\end{tabular}

${ }^{a}$ Adjusted for gender, age, total energy intake and iron intake; ${ }^{b}$ Adjusted for gender, age, total energy intake, iron intake and use of supplement containing Mn; ${ }^{\mathrm{c}}$ Adjusted for gender age, total energy intake, iron intake, use of supplement containing Mn and smoking habits; ${ }^{\mathrm{d} A d j u s t e d ~ f o r ~ g e n d e r, ~}$ age, total energy intake, iron intake, smoking habits and cadmium serum levels; ${ }^{\mathrm{P}} \mathrm{P}$ trend calculated using continuous values. OR, odds ratios; CI, confidence intervals; $\mathrm{PM}_{10}$, particulate matter $\leq 10 \mu \mathrm{m}$; Mn-Fer, Mn-ferritin; Mn-Tf, Mn-transferrin; Mn-Cit, Mn-citrate; Inorg-Mn, inorganic-Mn.

speciation analysis is of growing interest in medicine, due to the different, and in some cases opposite effects that could be yielded on target tissues by different species, as previously demonstrated for other trace elements, i.e., aluminium, lead and selenium (17,62-64) and recently for Mn $(65,66)$. Finally, the reliability of results did not appear to be affected by the values below the LOD, as shown by the sensitivity analyses.

This study has some limitations. First, dietary information was collected with self-administered questionnaires that although validated for the Northern Italian population (67), may still carry some inaccuracies and induce some exposure 
misclassification. Secondly, our sample size was small, due to difficulties in recruiting 'healthy' volunteers from the general population despite our efforts, thus, reducing the statistical power of the study, especially in subgroup analyses, as reflected by the generally wide CI of the point estimates. However, despite the limited sample size, the selection of study participants is unlikely to be biased as extraction was randomly performed and characteristics of included subjects appeared to be similar to those of the general Italian population $(68,69)$. Finally, we relied on PM assessment in outdoor air and not directly on airborne or deposited Mn levels. However, in a study carried out in Greece, the analysis of size distribution and composition of airborne particulate matter and associated $\mathrm{Mn}$ in the roadside environment showed that $\sim 1 / 3$ of $\mathrm{Mn}$ content is detected in coarse (i.e., $\mathrm{PM}_{10}$ ) particles (70). Furthermore, a similar study in the Paris region, demonstrated a higher contribution of $\mathrm{Mn}$ in the $\mathrm{PM}_{10}$ fraction, due to road dust resuspension, break and tire wear, and road wear abrasion (26).

In conclusion, our study is one of the few to assess the relation between total $\mathrm{Mn}$ levels and its species in serum, and the influence of different sources of exposure. In particular, the inverse correlation is of interest between meat intake and serum Mn concentrations, mainly Mn-Fer, probably due to the associated changes in iron intake. Another interesting finding was the positive correlation between vegetable and fruit intake and Mn levels, especially Mn-Cit. Finally, results suggest that $\mathrm{PM}_{10}$ exposure increases total $\mathrm{Mn}$ serum levels, while its relation with the single Mn species was inconsistent.

\section{References}

1. Guo T, Zhang L, Konermann A, Zhou H, Jin F and Liu W: Manganese superoxide dismutase is required to maintain osteoclast differentiation and function under static force. Sci Rep 5: 8016, 2015.

2. Lucchini RG, Martin CJ and Doney BC: From manganism to manganese-induced parkinsonism: A conceptual model based on the evolution of exposure. Neuromolecular Med 11: 311-321, 2009.

3. Williams M, Todd GD, Roney N, Crawford J, Coles C, McClure PR, Garey JD, Zaccaria K and Citra M: Toxicological Profile for Manganese. Agency for Toxic Substances and Disease Registry, Atlanta, GA, 2012.

4. Turconi G, Minoia C, Ronchi A and Roggi C: Dietary exposure estimates of twenty-one trace elements from a Total Diet Study carried out in Pavia, Northern Italy. Br J Nutr 101: 1200-1208, 2009.

5. Carlo Agostoni, Roberto Berni Canani, Susan Fairweather-Tait, Marina Heinonen, Hannu Korhonen, Sébastien La Vieille, Rosangela Marchelli, Ambroise Martin, Androniki Naska, Monika Neuhäuser-Berthold, et al: EFSA NDA Panel (EFSA Panel on Dietetic Products NaA: Scientific opinion on dietary reference values for manganese. EFSA J 11: 3419, 2013.

6. Meltzer HM, Brantsaeter AL, Borch-Iohnsen B, Ellingsen DG, Alexander J, Thomassen Y, Stigum H and Ydersbond TA: Low iron stores are related to higher blood concentrations of manganese, cobalt and cadmium in non-smoking, Norwegian women in the HUNT 2 study. Environ Res 110: 497-504, 2010.

7. Institute of Medicine (US) Panel on Micronutrients (eds): Manganese. In: Dietary Reference Intakes for Vitamin A, Vitamin K, Arsenic, Boron, Chromium, Copper, Iodine, Iron, Manganese, Molybdenum, Nickel, Silicon, Vanadium, and Zinc. National Academies Press, Washington, DC, 2001.

8. Greger JL, Davis CD, Suttie JW and Lyle BJ: Intake, serum concentrations, and urinary excretion of manganese by adult males. Am J Clin Nutr 51: 457-461, 1990.

9. Cockell KA, Bonacci G and Belonje B: Manganese content of soy or rice beverages is high in comparison to infant formulas. J Am Coll Nutr 23: 124-130, 2004.
10. Michalke B and Fernsebner K: New insights into manganese toxicity and speciation. J Trace Elem Med Biol 28: 106-116, 2014.

11. Pavilonis BT, Lioy PJ, Guazzetti S, Bostick BC, Donna F, Peli M, Zimmerman NJ, Bertrand P, Lucas E, Smith DR, et al: Manganese concentrations in soil and settled dust in an area with historic ferroalloy production. J Expo Sci Environ Epidemiol 25: 443-450, 2015.

12. Schroeder WH, Dobson M, Kane DM and Johnson ND: Toxic trace elements associated with airborne particulate matter: A review. JAPCA 37: 1267-1285, 1987.

13. Canepari S, Astolfi ML, Farao C, Maretto M, Frasca D, Marcoccia M and Perrino C: Seasonal variations in the chemical composition of particulate matter: A case study in the Po Valley. Part II: concentration and solubility of micro- and trace-elements. Environ Sci Pollut Res Int 21: 4010-4022, 2014.

14. Pappas RS, Gray N, Gonzalez-Jimenez N, Fresquez M and Watson CH: Triple Quad-ICP-MS measurement of toxic metals in mainstream cigarette smoke from spectrum research cigarettes. J Anal Toxicol 40: 43-48, 2016.

15. Freire C, Koifman RJ, Fujimoto D, de Oliveira Souza VC, Barbosa F Jr and Koifman S: Reference values of cadmium, arsenic and manganese in blood and factors associated with exposure levels among adult population of Rio Branco, Acre, Brazil. Chemosphere 128: 70-78, 2015.

16. Michalke B, Aslanoglou L, Ochsenkühn-Petropoulou M, Bergström B, Berthele A, Vinceti M, Lucio M and Lidén G: An approach for manganese biomonitoring using a manganese carrier switch in serum from transferrin to citrate at slightly elevated manganese concentration. J Trace Elem Med Biol 32: 145-154, 2015.

17. Vinceti M, Grill P, Malagoli C, Filippini T, Storani S, Malavolti M and Michalke B: Selenium speciation in human serum and its implications for epidemiologic research: A cross-sectional study. J Trace Elem Med Biol 31: 1-10, 2015.

18. Filippini T, Michalke B, Malagoli C, Grill P, Bottecchi I, Malavolti M, Vescovi L, Sieri S, Krogh V, Cherubini A, et al: Determinants of serum cadmium levels in a Northern Italy community: A cross-sectional study. Environ Res 150: 219-226, 2016.

19. Ebrahim AM, Eltayeb MH, Khalid H, Mohamed H, Abdalla W, Grill P and Michalke B: Study on selected trace elements and heavy metals in some popular medicinal plants from Sudan. J Nat Med 66: 671-679, 2012.

20. Jünemann AG, Stopa P, Michalke B, Chaudhri A, Reulbach U, Huchzermeyer C, Schlötzer-Schrehardt U, Kruse FE, Zrenner E and Rejdak R: Levels of aqueous humor trace elements in patients with non-exsudative age-related macular degeneration: A case-control study. PLoS One 8: e56734, 2013.

21. Pala V, Sieri S, Palli D, Salvini S, Berrino F, Bellegotti M, Frasca G, Tumino R, Sacerdote C, Fiorini L, et al: Diet in the Italian EPIC cohorts: Presentation of data and methodological issues. Tumori 89: 594-607, 2003.

22. Malavolti M, Malagoli C, Fiorentini C, Longo C, Farnetani F, Ricci C, Albertini G, Lanzoni A, Reggiani C, Virgili A, et al: Association between dietary vitamin $\mathrm{C}$ and risk of cutaneous melanoma in a population of Northern Italy. Int J Vitam Nutr Res 83: 291-298, 2013.

23. Malagoli C, Malavolti M, Agnoli C, Crespi CM, Fiorentini C, Farnetani F, Longo C, Ricci C, Albertini G, Lanzoni A, et al: Diet quality and risk of melanoma in an Italian population. $\mathrm{J}$ Nutr 145: 1800-1807, 2015.

24. Vinceti M, Rothman KJ, Crespi CM, Sterni A, Cherubini A, Guerra L, Maffeis G, Ferretti E, Fabbi S, Teggi S, et al: Leukemia risk in children exposed to benzene and $\mathrm{PM}_{10}$ from vehicular traffic: A case-control study in an Italian population. Eur J Epidemiol 27: 781-790, 2012.

25. Vinceti M, Malagoli C, Malavolti M, Cherubini A, Maffeis G, Rodolfi R, Heck JE, Astolfi G, Calzolari E and Nicolini F: Does maternal exposure to benzene and $\mathrm{PM}_{10}$ during pregnancy increase the risk of congenital anomalies? A population-based case-control study. Sci Total Environ 541: 444-450, 2016.

26. Poulakis E, Theodosi C, Bressi M, Sciare J, Ghersi V and Mihalopoulos N: Airborne mineral components and trace metals in Paris region: Spatial and temporal variability. Environ Sci Pollut Res Int 22: 14663-14672, 2015.

27. Li Z, Hopke PK, Husain L, Qureshi S, Dutkiewicz VA, Schwab JJ, Drewnick F and Demerjian KL: Sources of fine particle composition in New York city. Atmos Environ 38: 6521-6529, 2004. 
28. Vinceti M, Malagoli C, Teggi S, Fabbi S, Goldoni C, De Girolamo G, Ferrari P, Astolfi G, Rivieri F and Bergomi M: Adverse pregnancy outcomes in a population exposed to the emissions of a municipal waste incinerator. Sci Total Environ 407: 116-121, 2008.

29. Benson PE: Caline 4 - A dispersion model for predicting air pollution concentration near roadways. Department of Transportation, Division of New Technology and Research, Sacramento, CA, 1989.

30. Drufuca A,Battaiotto S, Bengo I, Rossi D and Torriani L: Variante Generale al Piano Territoriale di Coordinamento Provinciale. Procedura di simulazione della mobilità delle persone. Provincia di Modena-Polinomia, Milan, 2007 (In Italian).

31. Willett WC: Nutritional epidemiology. 3rd edition. Oxford University Press, New York, 2013.

32. Long JS: Regression models for categorical and limited dependent variables. Vol 7. Sage Publications, Inc., Thousand Oaks, 1997.

33. Helsel DR: More than obvious: Better methods for interpreting nondetect data. Environ Sci Technol 39: 419A-423A, 2005.

34. Zoni S and Lucchini RG: Manganese exposure: Cognitive, motor and behavioral effects on children: A review of recent findings. Curr Opin Pediatr 25: 255-260, 2013.

35. Rosa MJ, Benedetti C, Peli M, Donna F, Nazzaro M, Fedrighi C, Zoni S, Marcon A, Zimmerman N, Wright R, et al: Association between personal exposure to ambient metals and respiratory disease in Italian adolescents: A cross-sectional study. BMC Pulm Med 16: 6, 2016.

36. Vollet K, Haynes EN and Dietrich KN: Manganese exposure and cognition across the lifespan: Contemporary review and argument for biphasic dose-response health effects. Curr Environ Health Rep 3: 392-404, 2016

37. Minoia C, Sabbioni E, Apostoli P, Pietra R, Pozzoli L, Gallorini M, Nicolaou G, Alessio L and Capodaglio E: Trace element reference values in tissues from inhabitants of the European community. I. A study of 46 elements in urine, blood and serum of Italian subjects. Sci Total Environ 95: 89-105, 1990

38. Caroli S, Alimonti A, Coni E, Petrucci F, Senofonte O and Violante N: The assessment of reference values for elements in human biological tissues and fluids: A systematic review. Crit Rev Anal Chem 24: 363-398, 1994.

39. Alimonti A, Bocca B, Mannella E, Petrucci F, Zennaro F, Cotichini R, D'Ippolito C, Agresti A, Caimi S and Forte G: Assessment of reference values for selected elements in a healthy urban population. Ann Ist Super Sanita 41: 181-187, 2005.

40. Bocca B, Mattei D, Pino A and Alimonti A: Italian network for human biomonitoring of metals: Preliminary results from two regions. Ann Ist Super Sanita 46: 259-265, 2010.

41. Adamska-Dyniewska H, Trela R, Trojanowska B and Kowalska G: Serum manganese concentration in healthy population of the city of Lódź. Acta Physiol Pol 34: 299-303, 1983.

42. Iyengar V and Woittiez J: Trace elements in human clinical specimens: Evaluation of literature data to identify reference values. Clin Chem 34: 474-481, 1988.

43. Nève $J$ and Leclercq $N$ : Factors affecting determinations of manganese in serum by atomic absorption spectrometry. Clin Chem 37: 723-728, 1991.

44. Kapaki E, Zournas C, Kanias G, Zambelis T, Kakami A and Papageorgiou C: Essential trace element alterations in amyotrophic lateral sclerosis. J Neurol Sci 147: 171-175, 1997.

45. Rükgauer M, Klein J and Kruse-Jarres JD: Reference values for the trace elements copper, manganese, selenium, and zinc in the serum/plasma of children, adolescents, and adults. J Trace Elem Med Biol 11: 92-98, 1997.

46. Díaz C, López F, Henríquez P, Rodríguez E and Serra-MaJem L: Serum manganese concentrations in a representative sample of the Canarian population. Biol Trace Elem Res 80: 43-51, 2001.

47. Forrer R, Gautschi K and Lutz H: Simultaneous measurement of the trace elements $\mathrm{Al}, \mathrm{As}, \mathrm{B}, \mathrm{Be}, \mathrm{Cd}, \mathrm{Co}, \mathrm{Cu}, \mathrm{Fe}, \mathrm{Li}, \mathrm{Mn}, \mathrm{Mo}, \mathrm{Ni}$, $\mathrm{Rb}, \mathrm{Se}, \mathrm{Sr}$, and $\mathrm{Zn}$ in human serum and their reference ranges by ICP-MS. Biol Trace Elem Res 80: 77-93, 2001.

48. Torra M, Rodamilans M and Corbella J: Biological monitoring of environmental exposure to manganese in blood samples from residents of the city of Barcelona, Spain. Sci Total Environ 289: 237-241,2002

49. Baruthio F, Guillard O, Arnaud J, Pierre F and Zawislak R: Determination of manganese in biological materials by electrothermal atomic absorption spectrometry: A review. Clin Chem 34: 227-234, 1988 .

50. Yiin SJ, Lin HY, Yang MH, Shih TS and Lin TH: Pre-analytical for biological monitoring of manganese. Kaohsiung J Med Sci 14: 161-167, 1998.
51. Hodnett D, Wood DM, Raja K, Dargan PI and Shah AD: A healthy volunteer study to investigate trace element contamination of blood samples by stainless steel venepuncture needles. Clin Toxicol (Phila) 50: 99-107, 2012.

52. Sánchez C, López-Jurado M, Aranda P and Llopis J: Plasma levels of copper, manganese and selenium in an adult population in southern Spain: Influence of age, obesity and lifestyle factors. Sci Total Environ 408: 1014-1020, 2010.

53. Meltzer HM, Alexander J, Brantsæter AL, Borch-Iohnsen B, Ellingsen DG, Thomassen Y, Holmen J and Ydersbond TA: The impact of iron status and smoking on blood divalent metal concentrations in Norwegian women in the HUNT2 Study. J Trace Elem Med Biol 38: 165-173, 2016.

54. Eastman RR, Jursa TP, Benedetti C, Lucchini RG and Smith DR: Hair as a biomarker of environmental manganese exposure. Environ Sci Technol 47: 1629-1637, 2013.

55. Reiss B, Simpson CD, Baker MG, Stover B, Sheppard L and Seixas NS: Hair manganese as an exposure biomarker among welders. Ann Occup Hyg 60: 139-149, 2016.

56. Kim Y, Lobdell DT, Wright CW, Gocheva VV, Hudgens E and Bowler RM: Blood metal concentrations of manganese, lead, and cadmium in relation to serum ferritin levels in Ohio residents. Biol Trace Elem Res 165: 1-9, 2015.

57. Lucchini RG, Guazzetti S, Zoni S, Benedetti C, Fedrighi C, Peli M, Donna F, Bontempi E, Borgese L, Micheletti S, et al: Neurofunctional dopaminergic impairment in elderly after lifetime exposure to manganese. Neurotoxicology 45: 309-317, 2014.

58. Lucchini RG, Guazzetti S, Zoni S, Donna F, Peter S, Zacco A, Salmistraro M, Bontempi E, Zimmerman NJ and Smith DR: Tremor, olfactory and motor changes in Italian adolescents exposed to historical ferro-manganese emission. Neurotoxicology 33: 687-696, 2012.

59. Colledge MA, Julian JR, Gocheva VV, Beseler CL, Roels HA, Lobdell DT and Bowler RM: Characterization of air manganese exposure estimates for residents in two Ohio towns. J Air Waste Manag Assoc 65: 948-957, 2015.

60. Baldwin M, Mergler D, Larribe F, Bélanger S, Tardif R, Bilodeau L and Hudnell K: Bioindicator and exposure data for a population based study of manganese. Neurotoxicology 20: 343-353, 1999.

61. Hoet P, Vanmarcke E, Geens T, Deumer G, Haufroid V and Roels HA: Manganese in plasma: A promising biomarker of exposure to $\mathrm{Mn}$ in welders. A pilot study. Toxicol Lett 213: 69-74, 2012

62. Michalke B, Halbach $\mathrm{S}$ and Nischwitz V: JEM spotlight: Metal speciation related to neurotoxicity in humans. J Environ Monit 11: 939-954, 2009.

63. Vinceti M, Solovyev N, Mandrioli J, Crespi CM, Bonvicini F, Arcolin E, Georgoulopoulou E and Michalke B: Cerebrospinal fluid of newly diagnosed amyotrophic lateral sclerosis patients exhibits abnormal levels of selenium species including elevated selenite. Neurotoxicology 38: 25-32, 2013

64. Vinceti M, Ballotari P, Steinmaus C, Malagoli C, Luberto F, Malavolti M and Giorgi Rossi P: Long-term mortality patterns in a residential cohort exposed to inorganic selenium in drinking water. Environ Res 150: 348-356, 2016.

65. Neth K, Lucio M, Walker A, Kanawati B, Zorn J, SchmittKopplin P and Michalke B: Diverse serum manganese species affect brain metabolites depending on exposure conditions. Chem Res Toxicol 28: 1434-1442, 2015

66. Michalke B: Review about the manganese speciation project related to neurodegeneration: An analytical chemistry approach to increase the knowledge about manganese related parkinsonian symptoms. J Trace Elem Med Biol 37: 50-61, 2016.

67. Pasanisi P, Berrino F, Bellati C, Sieri S and Krogh V: Validity of the Italian EPIC questionnaire to assess past diet. IARC Sci Publ 156: 41-44, 2002.

68. Ferrante G, Minardi V, Possenti V, Quarchioni E, Masocco M, Salmaso S, Braggion M, Campostrini S and Baldissera S; Gruppo Tecnico PASSI: Smoke: Prevalence is decreasing, but the gap between socioeconomic categories remains. Epidemiol Prev 36: 371, 2012.

69. Gruppo Tecnico PASSI Emilia-Romagna: Sovrappeso e obesità in Emilia-Romagna: dati del sistema di sorveglianza PASSI (anni 2008-2011). 2012. http://www.epicentro.iss.it/passi/pdf2012/ EccessoPond PassiER 08 11.pdf (In Italian).

70. Samara C and Voutsa D: Size distribution of airborne particulate matter and associated heavy metals in the roadside environment. Chemosphere 59: 1197-1206, 2005. 